\title{
Engineering as a Pathway to Reintegration: Student Veterans' Transition Ex- perience into Higher Education and Civilian Society
}

\section{Dr. Jae Hoon Lim, University of North Carolina, Charlotte}

Jae Hoon Lim is an Associate Professor of Research Methods at the University of North Carolina Charlotte. Dr. Lim's research explores the intersection of gender, race, and class in STEM education and highlights the dialogical process of identity construction across various groups of underrepresented minorities in STEM fields. She has served as a co-PI and qualitative evaluator for two federal grants including a 1.6 million grant from the National Science Foundation. Her research has been published in many scholarly journals including Journal of Educational Psychology, Equity and Excellence in Education, and Race, Ethnicity, and Education. She is a contributing author to several books published by Oxford University Press, University of California Press, and Springer.

\section{Dr. Peter Thomas Tkacik, University of North Carolina, Charlotte}

Peter Tkacik is an Associate Professor of mechanical engineering within the motorsports focus area. His largest area of research is in the engagement of military veteran students and early career engineering college students through hands-on learning activities and exciting visual and experiential research programs. Other research activities are related to the details of the visual and experiential programs and relate to race car aerodynamics, vehicle dynamics, color-Schlieren shock and compressible flow imaging, and flows around multiple bodies in tandem.

\section{Claudia G Interiano, University of North Carolina, Charlotte}

MS in Clinical Mental Health Counseling at the University of Wisconsin-Stout through the Fulbright Scholarship. Doctoral student in the Counselor Education and Supervision program at the University of North Carolina-Charlotte.

\section{Mr. Jerry Lynn Dahlberg Jr, University of North Carolina, Charlotte}

Jerry Dahlberg is a graduate student and research assistant in the Department of Mechanical Engineering at the University of North Carolina at Charlotte. He received a B.S. degree in Mechanical Engineering Science in 2014 from the University of North Carolina at Charlotte. Jerry retired from the Army in 2010 as a Sergeant First Class. Through 21 years of service, he was involved in several combat and peacekeeping tours in the Balkans and Iraq. While on active duty, Jerry held numerous leadership positions to include Team Leader, Squad Leader, Provost Sergeant, Company Operation Sergeant, Platoon Sergeant, and Brigade Battle Staff NCO. He is interested in bluff body aerodynamics as well as propulsion systems for deep space travel. His graduate research focuses on instrumentation and experimental modeling of turbulence around bluff body shapes.

Ms. Caroline Elizabeth Nowell, University of North Carolina, Charlotte 


\section{Engineering as a Pathway to Reintegration: Student Veterans' Transition Experience into Higher Education and Civilian Society}

\section{Introduction}

In 2009, the Veterans Educational Assistance Act of 2008, also known as the Post 9/11 GI Bill, became the most significant educational benefit for military personnel. ${ }^{1}$ Higher education has become an attractive and feasible option for a substantial number of military veterans interested in gaining professional training to help them successfully reintegrate into civilian society. ${ }^{1,2}$ In 2013 , over 1 million student veterans were calculated to use educational benefits; a population projected to increase. ${ }^{1}$ In addition, 1 out of $5(20 \%)$ student veterans in college major in science, technology, engineering or mathematic (STEM) fields. ${ }^{3}$ Research on student veterans' transition into civilian society is critical at a time when higher education is serving as a critical medium for reintegration of this growing non-traditional student population.

Several scholars found that a constructive element in military veterans' integration into civilian society is college enrollment. ${ }^{4,5}$ Integration into civilian society is far from a seamless and smooth adjustment for many veterans. ${ }^{5}$ As veterans leave the military, they report a loss of structure, hierarchy, camaraderie, and a sense of altruism in their daily routine. ${ }^{6}$ Their previous professional and personal identity formulated through military training and experience is, at times, incompatible with careers in civilian society. ${ }^{7}$ Postsecondary institutions can function as critical settings that allow student veterans to connect prior military work with post-military professional aspirations.

Previous scholars have sought to understand the overall experience of student veterans. ${ }^{8,9}$ The existing literature shows that student veterans experience difficulty on multiple levels and undergo a complex transition. Moreover, student veterans present a unique set of needs for college and universities, as they are older than traditional students, married (44\%), and have dependents (52\%). ${ }^{3,9}$ However, there is a significant lack of research providing more thorough, concrete understanding about student veterans' transition to higher education, such as how a specific program in higher education may facilitate their successful reintegration into civilian society. This qualitative study explores the process of reintegration experienced by student veterans during their transition from military to higher education. In particular, we explored the experience of 20 engineering student veterans transitioning from the military to the field of engineering. We examined student veterans' motivation to enroll in an engineering program after military service, major challenges during the transition, and how they envision an engineering profession as a pathway to civilian reintegration.

\section{Theoretical Framework and Literature Review}

\section{Military Background}

To understand today's student veterans in engineering programs, it is important to understand the military culture and its impact on service members. ${ }^{2,5}$ Before entering or reentering higher education, student veterans have experienced socialization into a military culture 
that is considerably different from the culture in higher education. Scholarly research has shown that although each military branch may present a slightly different training focus, there are clear and consistent core cultural values in military life and duty. ${ }^{10}$ Through this perspective, the military can be defined as a culture with its own set of established values, norms, philosophies, customs and traditions. ${ }^{6,11}$ Research on military veterans shows that individuals enter the military between the ages of $18-20$, a critical period of identity formation. ${ }^{7}$ The beginning of their military career is governed by an indoctrination process colloquially known as "boot camp." This is an intensive process that requires soldiers to learn the "military way" of duty, honor, and loyalty. ${ }^{2}$ This socialization requires soldiers to mostly discard their sense of autonomy and individualism and adopt a collective identity with absolute commitment to comrades, military structure, and hierarchy. ${ }^{7}$ A career in the armed forces endorses a personal and professional identity considerably impacted by military socialization. The longer a military member's service, the deeper their military socialization, though even a short tour of duty can facilitate a strong military identity. ${ }^{2}$

Student veterans enter engineering programs after a military career, seasoned by the highest-quality training, standards, expectations, and equipment-usage. ${ }^{2}$ Due to the high-demand and altruistic nature of military jobs, many men and women in the military experience job satisfaction and pride. ${ }^{5,12}$ The visible impact of their work and service provides a clear sense of personal and professional purpose and social responsibility. Higher rank in the military also promotes leadership, respect, recognition and financial security for service members. Leadership, teamwork, and high levels of discipline are marked as essential values in the armed forces. ${ }^{13,14}$

\section{Civilian Society and Higher Education}

Given the intensity of military socialization, re-entering civilian life and becoming a student is an adjustment for many veterans. ${ }^{8}$ Previous research ${ }^{10,15}$ discusses that as student veterans enter civilian society, they encounter a culture that is very different from the one they left in the military. They often note that the dominant cultural values in U.S. civilian society and higher education - individuality, equality, personal achievement, and individual rights — conflict with military values. ${ }^{15,16}$ For some student veterans the military-civilian cultural gap creates significant difficulties in social, academic, and psychological areas. ${ }^{17}$

Furthermore, vocational readjustment is often an uphill battle for many student veterans who move from honorable and lucrative jobs to working as a full-time student. Research has shown that military veterans feel stigmatized and stripped of rank and honor if they experience struggles during this transition. ${ }^{5,14}$ Engineering departments, highly concentrated with math and science courses, present additional challenges for student veterans who have been out of school for a long period of time. Student veterans represent a population with special needs and challenges as they attempt to reintegrate into civilian society through higher education. ${ }^{2,4,12}$

\section{Student Veterans' Acculturation to U.S. Higher Education Culture}

Acculturation models offer a theoretical framework to explain student veterans' cultural conflict as they reintegrate into higher education. ${ }^{15}$ Acculturation is as a complex process of balancing cultural changes resulting from the encounter of two or more cultural groups. ${ }^{21}$ As student veterans (non-dominant group) enter the culture of higher education (dominant culture), 
acculturation models take into account the existence of peer differentiation and dynamics between both groups. Berry's acculturation model discussed four possible resolutions from this cultural exchange: (a) assimilation, (dismissal of prior cultural identity and acceptance of new culture), (b) separation (cultural retention of non-dominant culture and rejection of any new cultural beliefs, values, or practices), (c) marginalization (rejection of both cultures), and (d) integration (successful balance of cultural maintenance and participation between minority and dominant culture) ${ }^{21}$ (see Figure 1).

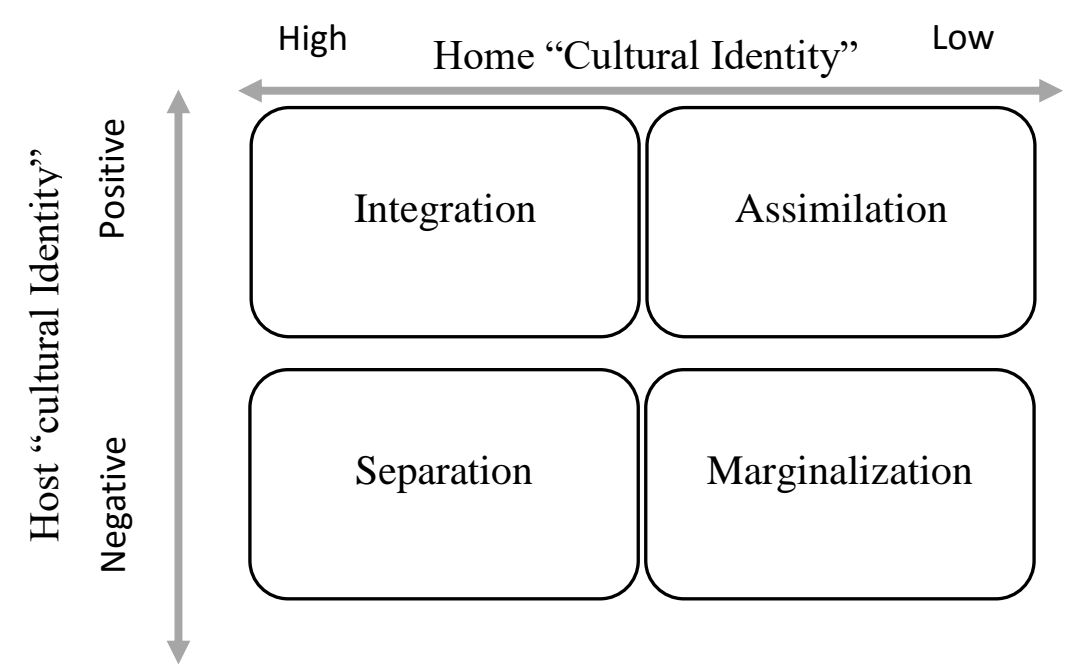

Figure 1. Berry's Acculturation Model

Recent overview of acculturation theories proposes that individuals acculturate through multiple dimensions identified as: behavioral acculturation (the ability to engage in cultural practices, such as appropriate language use and dress code), value acculturation (adoption of dominant cultural values), and identity acculturation (the degree of cultural identity) ${ }^{22}$ (see Figure 2). Changes among these dimensions occur simultaneously but independently for changes do not occur at the same rate or in the same direction. ${ }^{22}$ If acculturation comprises distinct components-both in terms of non-dominant and dominant cultural dimensions and in terms of practices, values and identifications, then acculturation is not a singular process that occurs at a single pace. A singular process that identifies an individual as "acculturated" or not, is likely an oversimplification of a very complex phenomenon. ${ }^{22}$ This model therefore considers student veterans' desire to retain cultural aspects of their military identity in college, while also connecting with the culture of higher education in different aspects. ${ }^{15}$ The expanded conceptualization of acculturation carries important implications for student veterans' reintegration into higher education and recognizes the significant role that higher education institutions play in this process. ${ }^{21,22}$ 


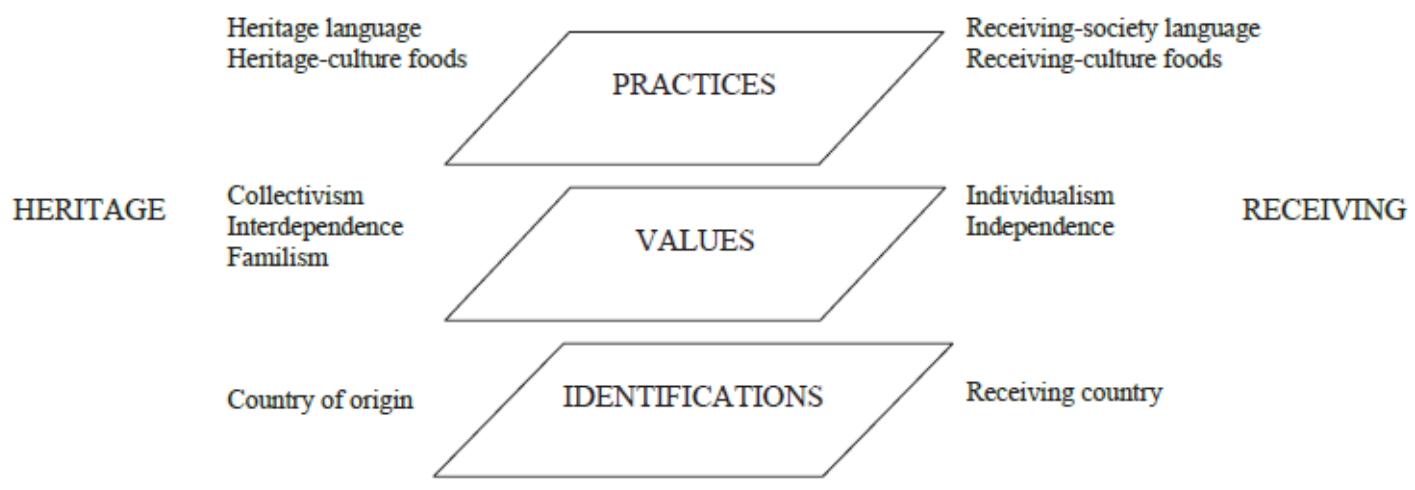

Figure 2. Multidimensionality of Acculturation

\section{Higher Education as a Pathway to Reintegration}

College students most often view higher education as an institution for development and pleasure, and research shows that the views of student veterans are not much different. ${ }^{18} \mathrm{~A}$ postsecondary institution can be a supportive environment where student veterans regain a sense of structure, support, and a positive sense of self. ${ }^{5,}{ }^{9}$ Higher education also helps student veterans develop academic competency and social skills that allow them to rebuild a professional identity in a specific discipline such as engineering. ${ }^{5}$ Although current research has highlighted the importance of higher education in supporting veterans' post-military career development, ${ }^{5}$ few studies have empirically explored the process of their career decision, academic pursuit, and professional identity formation in a specific field of study. The reintegration of a prior military experience and identity into a new, emerging professional career and civilian identity is a significant area for further research. Our study intends to address this void in the existing literature by investigating the role of military experience and identity in student veterans' career choice in engineering and how they envision the engineering profession as an ideal pathway for their integration into civilian society.

\section{Methods}

\section{Research Design}

The present study employed a phenomenological research design. The phenomenological approach is widely used in social research in order to explore people's experience in a particular setting and how individuals make sense of their experience in the given context. ${ }^{19}$ Phenomenological research is descriptive and exploratory in nature; its primary goal is to identify common threads in the lived experience of individuals under investigation. This design emphasizes the subjective interpretation of people and meaning developed at the intersection of individuals and society. ${ }^{20}$ Phenomenological research is relevant to this investigation because the goal is to understand student veterans' shared life experience and how they envision an engineering career as a desirable pathway in their post-military life. The lack of research on veteran students' transition experience also supports the value of more exploratory, in-depth phenomenological research on this topic., ${ }^{8,9}$ 


\section{Research Team}

The research team consisted of two faculty members, one Asian-American female and one Caucasian male, and three research assistants (one Caucasian male graduate student veteran, one Hispanic female graduate student, and one Caucasian female undergraduate student). Individual interviews were typically conducted by one graduate student. Group interviews with engineering student veterans were facilitated by the graduate research assistants and two graduate student veterans in engineering.

\section{Participants}

With the cooperation of the College of Engineering, participants were recruited by the research team through direct emails to student veterans. The engineering faculty and volunteer graduate student veteran focus group facilitators also assisted with the recruitment of veteran participants for the individual and group interviews. The email list of student veterans in the College of Engineering consisted of 72 male students, including 9 minority students (4 AfricanAmerican, 2 Hispanic, and 2 Asian-American students). There are currently no female student veterans enrolled in the College of Engineering. The sample of students was all male $(n=20)$ and primarily White $(n=19)$ with one Black male born outside of the United States. The participants served in the Army, Navy, Air Force, Marines, or National Guard and all of the veterans were pursuing degrees in either mechanical, civil, electrical or systems engineering, as well as engineering technology. Previous college experience varied among participants; some student veterans attended community college before current enrollment, while others had enrolled in higher education before joining the military. Most of the participants joined the military when they were 18 or 19 years old and were between the ages of 22-40 at the time of the interviews. Seven of the undergraduate students were currently married.

\begin{tabular}{llllll} 
TABLE 1 & & & & & \\
Participants & & & & \\
Pseudonym & Gender, Ethnicity & Academic Major & $\begin{array}{l}\text { Class standing (at } \\
\text { time of Data } \\
\text { Collection) }\end{array}$ & $\begin{array}{l}\text { Military Branch } \\
\text { (Years of } \\
\text { Service) }\end{array}$ & Type of Interview \\
\hline Saul & Male, Caucasian & Mechanical Engineering & Senior & Army (4) & Individual \\
Mitchell & Male, Caucasian & Mechanical Engineering & Senior & Army (4) & Individual \\
Steven & Male, Caucasian & Mechanical Engineering & Senior & Army (4) & Individual \\
Derek & Male, Caucasian & Mechanical Engineering & Junior & Air Force (20) & Individual \\
David & Male, Caucasian & Systems Engineering & Junior & Air Force (4) & Individual \\
Paul & Male, Caucasian & Mechanical Engineering & Sophomore & Navy (10) & Individual \\
Nicholas & Male, Caucasian & Mechanical Engineering & Senior & Army (5) & Individual, Group \\
Robert & $\begin{array}{l}\text { Male, Black born outside } \\
\text { the U.S. }\end{array}$ & Civil Engineering & Sophomore & Navy (4) & Group \\
Allan & Male, Caucasian & Mechanical Engineering & Senior & Marine Corps (4) & Group \\
Justin & Male, Caucasian & Mechanical Engineering & Senior & Marine Corps (4) & Individual, Group
\end{tabular}




\begin{tabular}{llllll} 
Maxwell & Male, Caucasian & Mechanical Engineering & Senior & Marine Corps (5) & Individual, Group \\
Anton & Male, Caucasian & Mechanical Engineering & Sophomore & Air Force (6) & Individual, Group \\
Jacob & Male, Caucasian & Mechanical Engineering & Senior & $\begin{array}{l}\text { National Guard } \\
(5)\end{array}$ & Group \\
Dayton & Male, Caucasian & Electrical Engineering & Sophomore & Navy (4) & Individual \\
Dean & Male, Caucasian & Engineering Technology & Sophomore & Army (21) & Individual \\
Shaun & Male, Caucasian & Mechanical Engineering & Junior & Marine Corps (3) & Individual \\
Peter & Male, Caucasian & Civil Engineering & Junior & Navy (6) & Individual \\
Dalton & Male, Caucasian & Mechanical Engineering & Sophomore & Navy (5) & Individual \\
Jason & Male, Caucasian & Mechanical Engineering & Senior & Army (20) & Individual, Group \\
\hline
\end{tabular}

\section{Interview Data Collection}

Data were collected using semi-structured individual and group interviews. The research team emailed upperclassmen (i.e., junior and senior) students first for individual interviews, followed by freshmen and sophomore students. Focus group interviews were promoted through the use of flyers and with the help of the engineering faculty and a volunteer graduate student veteran. Second and third emails were later sent to the entire group of student veterans to increase sample size. Understanding the importance of diversity, the research team tried various strategies to recruit more minority participants that included sending out multiple, individualized emails to minority student veterans, hiring an African-American graduate student to reach out for the small number of minority student veterans, and requesting referrals from a minority faculty member in the college. However, the final sample remained largely homogenous due to the overall demographics of the student population in the college and lack of positive response from minority student veterans. All student veterans who volunteered to participate were interviewed. Five of the twenty participants were interviewed twice - individually then later in a group. Individual interviews provided students with an opportunity to take time and reflect on their experience and to elaborate on their responses in a private space. Group interviews were later added in order to identify common experiences amongst student veterans in a supportive and friendly environment. The individual and group interviews typically lasted from 30 to 90 minutes and were later transcribed verbatim for analysis.

\section{Data Analysis and Strategies for Trustworthiness}

Qualitative data analysis is a dialogical interplay between data and theories/literature. Theoretical frameworks and existing literature play a significant role in sensitizing data and eliciting specific interpretations out of the data. Therefore, no qualitative analysis is free from the influence--either straightforward or subtle, of existing theories and research literature. However, phenomenological researchers highlight the importance of maintaining "a bridled attitude," the commitment to openness throughout the research process; this concept includes healthy tension between existing theories/literature and what should be seen or enacted from the narratives of participants' lived experiences. The primary purpose of phenomenological research is to shed light on the important facets of human experiences that are either less explored in the existing 
literature, or currently calling for a deeper, more holistic, or simply different understanding. ${ }^{19,20}$ As a result, Berry's acculturation theory and Schwartz et al.'s revised model served as a broad perspective in conceptualizing student veterans' transition experience as an acculturation process. At the same time, these theories were critically examined and interrogated, rather than dominated or determined what was possible to see, during data analysis. Respecting this phenomenological tradition of "bridling", the research team utilized an analytic strategy that helped create enough space for new ideas and interpretations to emerge in the initial stages of data analysis. More detailed aspects of student veterans' transition experiences were identified through inductive, open coding process. This bottom-up data analysis process ensured that interpretations were not overtly shaped by the given theoretical frameworks or existing literature but stay as close as possible to the authentic meanings as elaborated by our participants.

The research team employed four strategies throughout the entire research process in order to ensure the quality and trustworthiness of final outcomes, including member-checking, peer review, and researcher and theory triangulation. Verbatim interview transcripts were sent to each participant in order to obtain participants' confirmation and ensure accuracy. Participants were also encouraged to provide additional clarification or insights during this follow-up communication. Data were analyzed collaboratively by the entire research team. Several steps were taken to identify shared meaning and characteristics, which allowed the research team to create a set of open codes. The first step involved evaluating an independent summary that detailed key information about each participant. After reviewing all interview transcripts and participant summary profiles, an initial set of open codes was developed. These codes were descriptive in nature, small in scope, and based on key points made by the student veterans or important aspects of the student veterans' experiences in the engineering department. These small, descriptive open codes ensured that our initial analysis closely reflected the authentic voices of participants and meanings that they presented during interviews. Atlas ti, a qualitative analysis software, was then used in order to ensure consistency, transparency, and thoroughness in the coding process.

The research team held a series of weekly meetings to share and discuss the results of data analysis, revise the existing code list and create upper level categories based on commonalities across multiple open codes, and determine the direction and focus of subsequent analysis. This researcher triangulation is one of the key quality-ensuring strategies adopted in the study. The research team included five researchers, each with a distinct cultural, ethnic, and professional background including some with first-hand military experience which facilitated open discussion that maximized trustworthiness throughout the data collection and analysis. In the last stage of data analysis, the research team brought in the two acculturation models and critically examined the points of connections and contradictions between the models and major themes emerged from the analysis.

\section{Findings}

The majority of student veterans identified a clear connection between their prior military experience and new academic and professional goals, earning an engineering degree and becoming a professional engineer. There are three distinctive ways in which they made meaningful connections between their prior military work/identity and the new academic/ 
professional goals that they are currently pursuing as student veterans in engineering (see Figure $3)$.

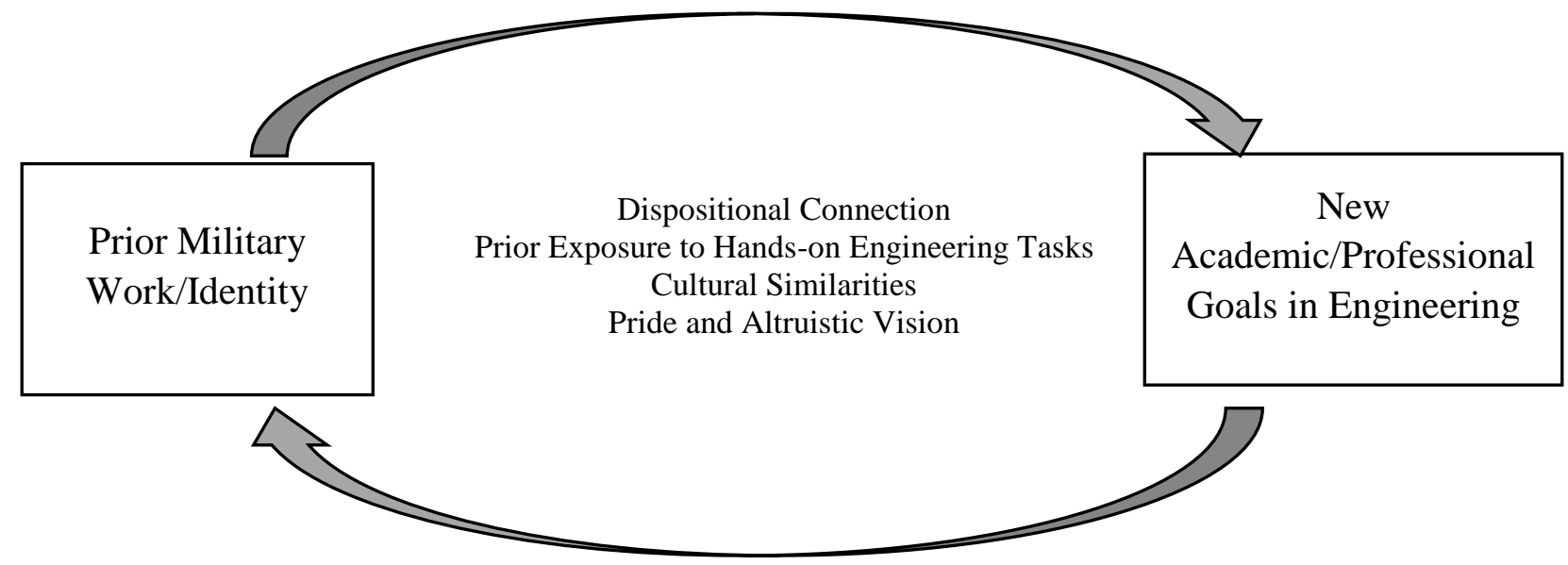

Figure 3. Salient Findings for Student Veterans in the College of Engineering

\section{Dispositional Connection}

All participants acknowledged that specific skills and dispositions they had gained during military years contributed to their academic success in the demanding environment of engineering. Among the most highlighted dispositions, the participants mentioned perseverance, stress and time management, leadership and teamwork skills. Student veterans shared that their military training influenced a "goal-driven mindset". Perseverance was required in the military; giving up in any circumstance was not an option. "The military trains you to be obsessive about one thing: your job," explains Paul, a Navy student veteran. When he became a student, Paul described how his goal shifted, "When I made the decision [to come back to college] I turned that obsession to schoolwork." Many student veterans resorted to this obsessively "goal-driven mindset" to maintain their "drive," "motivation," and "ability to follow through" when school work became difficult and challenging. This mindset proved to be pivotal to their success in the engineering program, loaded with a stringent curriculum demand and inflexible, long lab hours. Peter, a Navy student veteran, further explains how perseverance and a goal-driven mindset proves to be a constant in engineering,

Engineering is hard. It takes a lot of brute force studying. You don't get it? Do it again. You sort of get it? Do it again. Ok, I'm getting better. Do it again. Now I think I can do it. Do it again and then do it one more time after that and that's what it takes.

Many student veterans recollected their military experience as highly stressful, with long and demanding work hours. After experiences high levels of stress throughout their military career, handling stress related to school work seemed like much less of a challenge. "No one's life is in danger with me writing down this equation on a piece of paper", explained Maxwell, a 
Marine Corps student veteran, as he compared his stress levels in the military to college-level stress. The participants shared that their military training prepared them to meet class obligations, since they had no trouble waking up early for classes, prioritizing and organizing student responsibilities, or working on assignments that require extensive work hours.

Leadership and teamwork skills are essential professional dispositions in the military. ${ }^{7}$ Based on its hierarchical structure, the military's success comes from the ability of service men and women to carry out their assignments as leaders and in teams. "We either sail as a ship, or sink as a ship," stated Derek, an Air Force veteran who retired at the E7 rank after 20 years. Like Derek, several other student veterans had held leadership positions earlier on in their military career. All student veterans recollected acquiring teamwork skills in the military. As student veterans enrolled in engineering programs, these dispositions naturally transferred to the classroom. Dalton, a Navy student veteran discusses this transition,

In group projects I find myself taking the lead and telling people how to organize their work and making sure everything is done on time. I find myself using my experience leading teams to accomplish certain goals.

Participants in this study state that each disposition is important for their survival or success in their engineering program. Their military training became an asset during their transition to higher education. Engineering is considered challenging and time consuming by many, but all of the student veterans stated that the strong work ethic they developed during the military years as well as the dedication and determination required of a military member helped them focus on their studies and avoid unnecessary distractions.

\section{Prior Exposure to Hands-on Engineering Tasks}

Student veterans saw engineering as a bridge that connected their prior military work with their post-military professional aspirations. Many student veterans had military work experience that required technical knowledge and mechanical skills. They discussed how their military assignments entailed forms of "hands-on engineering experience". Exposure to basic engineering tasks in the military, whether electrical, electro-mechanical, or mechanically based, provided familiarity with engineering tasks and a window into an engineering career. This familiarity served for many students as the basis for their decision to enroll in an engineering program. Dean, an Army student veteran, describes how his military assignment unfolded into an interest in a future engineering career.

I was a prime power production specialist. The prime power production specialist does base camp power to everything like dining facilities and warehouses. When you're in a combat zone, certified electrical engineers do not want to go into combat zones, but there is still electrical engineering that has to be done. There were times where I was actually doing design work because I was the most qualified person on the ground.

Through their technical work experience in the military, student veterans felt confident in their ability to pursue an engineering career. Their previous work experience provided a general idea of what to expect when working in the engineering field. Several student veterans 
expressed that their exposure to the military and combat zones motivated them to pursue defense engineering. Many participants stated that they enjoyed hands-on experiences where they learned firsthand what engineering does and can do in real-world situations. "It's hard to understand what those guys really need unless you've been there," stated Nicholas, an Army student veteran as he explained how non-veteran engineers fail to understand the technological needs of military servicemen in the field.

\section{Cultural Similarities}

Overall, student veterans shared a sense of comfort and enjoyment in the engineering program. All student veterans stated finding similarities between military and engineering cultures. Student veterans acknowledged that masculine norms and values, such as being strong and blunt and direct in speech and behavior and a common use of jargons and slangs are essential social codes of the U.S. military culture. As a male-dominant program, participants mentioned that engineering shared comparable social norms. The all-male group of participants found a possibility of re-creating a sense of "camaraderie" in their engineering program as they reintegrated into higher education. Student veterans also felt compatible to engineers' mindset and communications styles. Their prior military experience was relatable to the terminology learned throughout their program, as evidenced by Derek's example of two student veterans applying military terms to a Physics assignment,

A veteran can look at one of the examples we had such as a bird flying and calculating a Physics trajectory problem where you're looking at the $\mathrm{x}$ component and the y component. Well somebody who's been in the Airforce, they'd be like, "OK, what did you do for a living? Bomb loader? Ok, you have an F16 flying over and he drops a bomb and wants to hit this target." Now I'm more in tune because the same forces are applicable. Even though the weight of the object is different, now I can flow with it because that's an interest of mine.

In addition, student veterans stated that pursuing an engineering career provided similar financial stability and job satisfaction that they had obtained in the military. David, an Air Force student veteran, found that in terms of pay and satisfaction "almost all of the top undergraduate jobs...6 out of 10 of them [were] engineering positions." Financial stability is one of the major concerns of almost all student veterans in the study. Therefore, the high income and stable financial future expected from the engineering field was an important factor as student veterans made the decision to choose an engineering career over other possibilities.

\section{Pride and Altruistic Vision}

Student veterans possessed deep pride in their veteran identity and viewed themselves as having provided valuable service to people and society. As a result, they expressed a strong desire to remain or reemerge as a contributing member of society. Engineering was viewed as a profession that helps sustain their pride and altruistic desires. Following a successful and respectful professional career in the military, some student veterans felt anxious about becoming "just another" student. After 20 years in the military, Derek expressed his anxiety about becoming a new student. "I was very shaky coming back into school because it is all about 
academics." However, by successfully navigating challenges faced in academia, Derek, like many other student veterans, regained a sense of confidence and self-assurance.

Student veterans' narratives describe different attempts to balance their prior core military and their post-military professional identities. As a retired veteran with 20 years of leadership experience, Jason expressed gaining a sense of pride by returning to a similar position of authority,

For every class, within the first five minutes of announcing a project, either the group decided that I was going to do [lead], I decided, or the faculty decided. Even in my junior design and senior design projects, it was a natural transition

Some veterans expressed a desire to work in an occupation that provides a sense of purpose and social responsibility that they had experienced in their military jobs. Many participants expressed that the field of engineering was one of the few professional careers that bestow this sense of purpose and social responsibility in civilian society. David expressed that for many student veterans, engineering reinstated the feeling that "what you're doing matters." Nicholas reiterated that the professional altruism in engineering also impacted his personal identity,

I have a real hard time seeing myself doing anything other than this [engineering]. It's come to be a measure of who I am. You think of yourself in some ways based on what you do.

More than half of the student veterans expressed a profound sense of pride about their service; they expressed conviction that they earnestly served society as honorable members of the military. Student veterans sought to reclaim their pride in service through an engineering career which they also viewed as a profession that serves people and society. Many student veterans also felt that engineering jobs entailed social responsibility. Peter details why many student veterans find engineering relatable to their military service,

Well, it's the seriousness of it. Even though somebody's life isn't on the line, there are safety issues. Also, it's not necessarily that lives are on the line but there's a lot of money on the line. So the seriousness of the job obviously translates.

An engineering career was not just a job to the student veterans in our study; it was a way to reconnect to their treasured identify as servicemen and to construct a civilian life with the same pride and sense of responsibility that they once had in the military.

\section{Discussions}

This study highlights several important points that have been illustrated in the existing literature to some extent, yet largely ignored due to the prevalence of deficiency perspective in research on student veterans. Military servicemen undergo intense training in order to successfully complete the arduous and dangerous missions they are assigned. ${ }^{10}$ Recruits adopt military cultural values-persistency, a goal-oriented mindset, teamwork, self-discipline, and leadership-throughout their military career development. ${ }^{12}$ For many student veterans, the knowledge, skills and dispositional qualities accumulated during their military service also support their successful transition and academic success in higher education. Research discussing 
student veterans' challenges in higher education, ${ }^{8,9}$ should not obfuscate evidence showing that this group of nontraditional students has the potential and necessary dispositions to thrive in a collegiate environment. Student veterans should not be viewed from a deficiency perspective; they should be conceptualized as individuals possessing a unique set of knowledge, skills, and dispositions that ultimately support their successful civilian life if properly supported in higher education and society.

Previous research ${ }^{10,15}$ indicates a cultural gap between military and civilian contexts that can significantly impact student veterans' transition. Our study suggests that cultural compatibility may exist between military and engineering program environments. Military culture fosters leadership, teamwork, highly structured chain of commands, and an aggressivemale dominant ethos. ${ }^{13,14}$ Similarly, engineering is a fact-driven, team-based field dominated by males. Its cultural contexts and relational norms provide a more relaxing and permissible environment for student veterans who are still in the process of adapting to civilian cultural norms. Student veterans recognized that some military cultural values, such as their common use of direct and blunt language, could be misunderstood among civilians. Entering a discipline that shared some similar characteristics allowed student veterans to reintegrate their previously acquired professional and personal identity.

Our study presents positive and strong evidence that engineering programs have a special role in supporting veterans' successful transition to civilian society. Student veterans saw engineering as a bridge that connected their prior military work and their post-military professional aspirations. Vocational readjustment is an uphill battle for many military servicemen as they leave their honorable and lucrative military jobs. Research has shown that military veterans feel stigmatized and stripped of rank and honor if they experience difficulty during this transition. ${ }^{5,14}$ Engineering programs can provide a successful transition pathway where student veterans regain a sense of structure, support, and a positive sense of self. ${ }^{5,9}$ Student veterans exposed to hands-on-engineering work during the military can transfer their military knowledge, skills, and dispositions as prospective engineers. Student veterans who developed an affinity for engineering during military service expressed high confidence and motivation to acquire the academic and professional skills required of engineers and to rebuild a professional identity in the engineering field. ${ }^{5}$ The engineering profession can also assist student veterans in their attempt to sustain a sense of pride and altruistic desire to serve their community. Navigating a new environment where a sense of purpose in life is lost is one of most fundamental challenges student veterans face transitioning. ${ }^{7}$ Entering the engineering profession where they can once again serve people and society, revived student veterans' sense of purpose and offered them a drive to reintegrate as productive members of society.

Like many other studies, this study is not without limitations. In addition to the small sample size that is inherent in most qualitative research, the most significant limitation is the lack of gender and racial diversity in the sample. The lack of demographic diversity in the engineering program itself and use of volunteerism resulted in an all-male, predominantly Caucasian sample. As a result, we strongly recommend that future studies create a sample with significant gender, racial, and cultural diversity in order to elicit a more inclusive and holistic account of student veterans' experience of acculturation in the field of engineering. Increasing the sample size with more gender and racial diversity would also help researchers carry out a 
meaningful sub-group comparison, which will lead to a more in-depth examination across multiple factors identified in this paper.

Biographical Information

1. U.S. Department of Veteran Affairs. Veterans' Benefit Administration. Washington, D.C.: Annual Benefits Report Fiscal Year 2013, 2013.

2. Vacchi, D. (2012). Considering student veterans on the twenty-first-century college campus. About Campus , $15-21$.

3. American Council on Education. (2014). Higher Ed. Spotlight: Undergradute Student Veterans. Washington, DC: Author .

4. Mangan, K. (2009). Colleges help veterans advance from combat to classroom. Chronicle of Higher Education. Retrieved June 2015, from http://chronicle.com/article/Colleges-Help-Veterans-Adva/48846/

5. DiRamio, D., \& Jarvis, K. (2011). Old friends and new faces. ASHE Higher Education Report, 37(3), 1-144.

6. Hall, L. (2011). The importance of understanding miilitary culture. Social Work in Health Care, 50(1), 4-18.

7. Reisser, L. (2011). Crisis of Identity? Veteran, Civilian, Student. In D. DiRamio, \& K. Jarvis, Old friends and new faces (pp. 53-65). Veterans in Higher Education.

8. Ackerman, R., DiRamio, D., \& Mitchell, R. (2009, Summer). Transitions: Combat veterans as college students. New Directions for Student Services, 126, 5-14. doi:10.1002/ss.311.

9. Rummann, C., \& Hamrick, F. (2010). Student soldiers in transition: Re-enrolling. Journal of Higher Education, 431-458.

10. Demers, A. (2011). When veterans return: The role of community in reintegration. Journal of Loss and Trauma, $16,160-179$.

11. Reger, M., Etherage, J., Reger, G., \& Gahm, G. (2008). Civilian psychologists in an army culture: The ethical challenge of cultural competence. Military Psychology, 20, 21-35.

12. DiRamio, D., Ackerman, R., \& Garza, R. (2008). From combat to campus: Voices of student veterans. NASPA Journal, 45(1), 73-102.

13. Collins, J. (1998). The complex context of American military culture: A practitioner's view. The Washington Quarterly, 21(4), 213-228.

14. Demers, A. (2013). From death to life: Female veterans, identity, negotiation, and reintegration into society. Journal of Humanistic Psychology, 53(4), 489-515.

15. Arminio, J., Kudo Grabosky, T., \& Lang, J. (2015). Student Veterans and Service Members in Higher Education. New York, NY : Routhledge.

16. Hofstede, H. (2001). Culture's Consequences (2nd ed.). Thousand Oaks, CA: Sage .

17. Stritikus, T., \& Nguyen, D. (2007). Strategic transformation: Cultural and gender identity negotiation in firstgeneration Vietnamese youth. American Educational Research Journal, 44(4), 853-895.

18. Moffat, M. (1991). Undergraduate culture and higher education. The Journal of Higher Education, 62(1), 4461.

19. Hays, D., \& Singh, A. A. (2011). Qualitative inquiry in clinical and educational settings. Guilford Press.

20. Merriam, S. (2002). Qualitative Research in Practice: Examples for discussion and analysis. San Francisco: Jossey-Bass.

21. Berry, J. (1997). Immigration, acculturation, adaptation. Applied Psychology: An International Review, 46(1), $5-68$.

22. Schwartz, S., Unger, J., Zamboanga, B., \& Szapocznik, J. (2010). Rethinking the concept of acculturation: Implications for theory and research. American Psychologist, 65(4), 237-251. doi:10.1037/a0019330 


